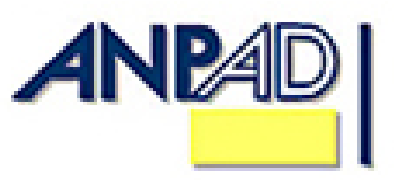

Disponível em

http://www.anpad.org.br/rac

RAC, Curitiba, v. 14, n. 4

pp. 744-751, Jul./Ago. 2010

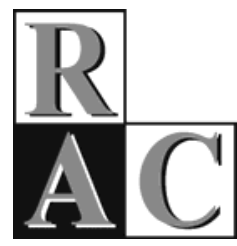

Documentos e Debates:

\title{
Réplica 2 - A Estrutura Intelectual da Produção Científica de Alianças Estratégicas: Impressionismo ou Realismo?
}

The Intellectual Structure of Strategic Alliance Scientific Production: Impressionism or Realism?

Jorge Ferreira da Silva * Doutor em Engenharia de Produção pela PUC-Rio. Coordenador de Pós Graduação em Administração de Empresas da PUC-Rio, Rio de Janeiro/RJ, Brasil.

Ângela da Rocha Doutora em Administração pelo IESE. Professora da PUC-Rio, Rio de Janeiro/RJ, Brasil.

\footnotetext{
* Endereço: Jorge Ferreira da Silva

PUC-Rio - Centro de Ciências Sociais, Depto. de Administração. Rua Marquês de São Vicente, 225, Gávea, Rio de Janeiro/RJ, 22453-900. Email: shopshop@iag.puc-rio.br
}

Copyright (C) 2010 RAC. Todos os direitos, inclusive de tradução, são reservados. É permitido citar parte de artigos sem autorização prévia desde que seja identificada a fonte. 


\section{INTRODUÇÃO}

É louvável o esforço empreendido pelos autores para realizar ampla revisão da literatura sobre alianças estratégicas, proporcionando algumas idéias relevantes sobre quais seriam as principais vertentes teóricas que abordam a temática da cooperação e parceria, avaliando como elas se podem articular entre si, envolvendo questões fundamentais do processo estratégico, a cooperação e o ambiente. O documento 'Cooperação e Alianças: Perspectivas Teóricas e suas Articulações no Contexto do Pensamento Estratégico' contribui para identificar algumas teorias relevantes, aplicadas à pesquisa de alianças estratégicas, embora deixe em segundo plano a questão das articulações entre elas.

Sem dúvida, esforços desta natureza são úteis e desejáveis para o progresso de um campo de estudos. Aliás, os autores reconhecem plenamente que o trabalho 'não pretende esgotar o assunto', mas 'busca sinalizar caminhos interessantes e atraentes de investigações sobre alianças e estratégias colaborativas' É natural que o amadurecimento de uma disciplina provoque análises desta natureza, na maior parte das vezes aplicando a abordagem impressionista, que tende a refletir as visões subjetivas dos autores, como é o caso.

Nesta réplica, ao contrário do documento de referência, a não existência de teoria única para apoiar tema de tal amplitude é pressuposto e não conclusão. A Física tem ensinado que uma theory of everything não tem sustentação empírica, graças à incompatibilidade da mecânica quântica com a teoria geral da relatividade. É natural esperar que sistemas socio-técnicos com a complexidade das alianças estratégicas, contendo tais incompatibilidades por construção, também não disponham de uma theory of everything particular.

É sugerido, neste ensaio, que os esforços de classificação são ainda prematuros, dada a necessidade de entender, em um passo inicial, a complexa inter-relação desses campos teóricos, e construir, em um segundo passo, um sistema de classificação que leve em conta os temas centrais das teorias, sua eventual comunalidade de origem, e sua herança de outras teorias.

\section{A COMPLEXIDADE DO CAMPO DE ESTUDOS}

Antes de ser discutido o problema central de que trata este ensaio, que é a classificação da literatura sobre alianças estratégicas, cabe chamar a atenção para a complexidade desse campo de estudos. Barney (2006) reconhece dois tipos de estratégias colaborativas: alianças estratégicas e conluio tácito. Nesse último caso, as empresas atuantes em uma indústria colaborariam com o propósito de reduzir o nível de competição na indústria. O conluio tácito é um caso específico que não interessa aqui. Assim, pode ser considerado que, para efeitos deste ensaio, os termos alianças estratégicas e estratégias colaborativas podem ser usadas como substitutos um do outro. Observe-se, ainda, a grande variedade de expressões usadas para se referir a alianças, tais como parcerias, parcerias de valor agregado, arranjos colaborativos, co-alinhamentos, marketing simbiótico, coalizões, coligações, constelações, redes estratégicas, quase-fusões e híbridos, entre outros. Expressões como competição coletiva (Gomes-Casseres, 1996) e capitalismo de alianças (Dunning, 1995) vêm sendo usadas para expressar essa nova forma de organização empresarial.

São tantas as definições utilizadas por vários autores e as diferentes nuances associadas, que se poderia dedicar todo um artigo simplesmente a discutir o domínio conceitual do construto aliança estratégica. Williamson (1975), por exemplo, concebe as alianças como formas híbridas entre os extremos dos relacionamentos governados pelo mercado e do controle integral da hierarquia. Nessa posição intermediária, as empresas envolvidas em alianças utilizariam a seu favor os benefícios dos mecanismos naturais do mercado, sem ter de incorrer nos custos e possíveis ineficiências do controle 
hierárquico, sujeitando-se, porém, ao potencial comportamento oportunista de parceiros. Para Kogut (2000), porém, a emergência de um padrão estrutural de comportamento colaborativo não seria o resultado de alguma escolha abstrata entre mercado e hierarquia, mas derivaria das condições específicas iniciais de qualquer indústria. Klein e Zif (1994, p. 53), por sua vez, veem as alianças como "arranjos entre empresas separadas, e atividades encadeadas, indo além do escopo de transações no mercado competitivo ... [podendo] ser vistas como meio-termo entre contratos formais e fusões". Para Astley e Fombrun (1983), são uma forma de gerenciar a mudança derivada da interdependência organizacional, e para Gulati (1998, p. 29) "arranjos voluntários entre firmas, que envolvem troca, compartilhamento e co-desenvolvimento de produtos, tecnologias, ou serviços”. Esses são apenas alguns exemplos da grande diversidade de conceitos e definições existentes na literatura.

São também inúmeras as tentativas de classificação de alianças. As classificações existentes levam em conta: formato da aliança, estágio na cadeia de valor, função para a qual a aliança está sendo formada, escopo, cobertura de mercado, forças e fraquezas da empresa, tipo de relacionamento contratual, forma de alocação de recursos e conflito potencial, entre outros (Pinho, 1998). Tais classificações, quase invariavelmente, são bem específicas, centrando-se em um aspecto particular das alianças. Caracterizam-se, tipicamente, como simples esquemas conceituais.

Ao fim e ao cabo, a complexidade da disciplina, começando pelo próprio conceito de alianças estratégicas, passando pelas diversas teorias articuladas que sustentam as inúmeras investigações sobre o tema, como, por exemplo, a Teoria das Opções Reais e o Paradigma Eclético da Produção Internacional, para citar algumas não incluídas no documento de referência, e culminando com os impactos derivados no construto de desempenho, prescreve estratégias de análise mais cautelosas.

\section{A Prematuridade dos Sistemas de ClassificaÇÃo, TAXonomias e TIPOlOGIAS}

Possivelmente uma das áreas em que mais se têm realizado perigosas incursões pelos labirintos da ignorância é aquela que trata de classificação. É comum na área de Administração que os autores proponham esquemas classificatórios, tipologias ou taxonomias para fenômenos organizacionais sem conhecerem os princípios que regem sua formulação. Como resultado, tais propostas são frequentemente sujeitas a severas críticas (Doty \& Glick, 1994).

Sistemas de classificação (Rich, 1992) são geralmente de três tipos: esquemas classificatórios, tipologias e taxonomias. O ponto de partida é que os sistemas de classificação se constroem a partir da identificação e contraste de diversidades e uniformidades. No entanto, ao passo que os esquemas classificatórios se ocupam da "identificação e alocação de [objetos] ... a categorias formalmente reconhecidas", as tipologias e taxonomias se referem ao "desenvolvimento de uma teoria de diferenças” (McKelvey, 1978, p. 1428). A principal diferença entre esquemas classificatórios e tipologias e taxonomias é, portanto, esta: as duas últimas utilizam uma teoria subjacente, enquanto os primeiros trabalham apenas com um conjunto de classes. No entanto, é frequente a confusão semântica (Meyer, Tsui, \& Hinnings, 1993) em torno desses termos.

O propósito dos esquemas classificatórios é "proporcionar um conjunto de regras de decisão para alocar categoricamente [objetos] ... a grupos heterogêneos que, agrupados, constituem um conjunto mutuamente excludente e exaustivo" (Doty \& Glick, 1994, p. 232). Portanto, as classes, nos esquemas classificatórios, devem atender a duas propriedades fundamentais: ser (i) mutuamente excludentes; e (ii) exaustivas. Chrisman, Hofer e Boulton (1988) consideram que os esquemas classificatórios tenderiam a ser univariados, mas não há consenso a esse respeito.

Os termos tipologia e taxonomia são por vezes usados de forma intercambiável por diversos autores, mas há consenso, qualquer que seja o termo utilizado, quanto ao fato de que deve haver uma construção teórica (uma 'teoria das diferenças') e que a simples derivação empírica não obedece a esse 
princípio fundamental. Tipologias e taxonomias, contrariamente aos simples esquemas classificatórios, têm como requisito básico, portanto, a existência de uma teoria subjacente.

Para evitar maiores confusões ao leitor, será utilizado neste ensaio o significado geralmente atribuído a esses termos (Miller, 1996), considerando tipologias como "conjuntos de configurações derivados conceitualmente", e taxonomias como "conjuntos de configurações derivados empiricamente” (Meyer et al., 1993, p. 1182).

Serão tratadas inicialmente as tipologias. Como foi visto, as tipologias são, essencialmente, uma teoria das diferenças entre objetos pertencentes a uma dada população derivada de um referencial teórico pré-existente. A teoria proporciona as bases filosóficas sobre as quais se assenta o sistema de classificação; a explicação necessária para a classificação (por que usar aquelas classes); os temas centrais que regem a classificação; os tipos de variáveis a serem utilizados; as relações complexas entre essas variáveis; e as fronteiras entre os grupos (Rich, 1992). Miller (1996) atribui as seguintes características às tipologias: baseiam-se na teoria e utilizam diferenças e relações conceitualmente relevantes; os tipos ideais sugeridos contêm elementos de contraste que facilitam a pesquisa empírica; e os elementos usados para construir os tipos são coerentes do ponto de vista temático e têm implicações para o desenvolvimento conceitual e normativo. Doty e Glick (1994) oferecem os seguintes critérios para que uma classificação seja enquadrada como teoria (e não como simples esquema classificatório): (i) existência de construtos (tipos ideais e dimensões usadas para descrevêlos); (ii) identificação das relações entre os construtos (consistência interna dos tipos ideais); (iii) falsificabilidade (a tipologia pode ser testada empiricamente e estar sujeita a desconfirmação).

Já as taxonomias são derivadas empiricamente, utilizando-se normalmente de métodos de estatística multivariada. Há basicamente duas etapas no desenvolvimento de taxonomias. A primeira envolve construir a priori hipóteses sobre as classes, e a segunda o teste empírico dessas classes. Dessa forma, também a construção de taxonomias não deve fugir ao desenvolvimento teórico. Sem isso, uma taxonomia corre o risco de incorrer no "mito da geração de hipóteses indutivas", a que Popper (1978, p. 46) faz referência: "a crença de que podemos começar apenas com a pura observação, sem nada que seja da natureza de uma teoria, é absurda".

Miller (1996, p. 507) faz referência às críticas às taxonomias, provenientes de vários autores, quanto à "falta de significância teórica”, "seleção arbitrária e limitada de variáveis" e "resultados não confiáveis ou instáveis”. Carper e Snizek (1980) observaram que as taxonomias totalmente derivadas empiricamente, de forma geral, apresentam problemas de validade externa, não sendo aplicáveis a outras situações. Eles atribuem os problemas associados a taxonomias ao excesso de preocupação com o uso de técnicas estatísticas sofisticadas, em detrimento de uma construção teórica que guie o trabalho empírico: "quando se trata de tipologias totalmente construídas de forma empírica, a situação tem sido, frequentemente, a de colocar a cauda metodológica à frente do cachorro teórico” (pp. 73-74).

Para Chrisman et al. (1988), uma taxonomia deve atender aos seguintes requisitos: (i) incluir todas as características relevantes do fenômeno estudado; (ii) ter aplicação geral e não específica; (iii) ser parcimoniosa; (iv) ter natureza hierárquica (ou seja, basear-se em dois ou mais níveis categóricos); e (v) ser intemporal (e, portanto, aplicável a qualquer período de tempo, passado e futuro). Por sua vez, as taxa (conjuntos de objetos semelhantes entre si e distintos dos demais, ou grupos derivados empiricamente) devem obedecer aos seguintes requisitos: (i) ser mutuamente excludentes; (ii) ser internamente homogêneas (membros de uma taxon devem ser mais semelhantes entre si do que aos membros de outras taxa); (iii) coletivamente exaustivas (cada caso deve ser enquadrável em alguma taxon); (iv) estáveis (não serem alteradas significativamente por outros testes empíricos, a menos que haja mudanças intrínsecas nos objetos); além de (v) serem nomeadas de forma relevante.

Agora existem condições, à luz dos conceitos enunciados nesta seção, de rever a classificação proposta por Vale e Lopes no artigo objeto deste ensaio. Em linhas gerais, não é possível enquadrar este trabalho rigorosamente em nenhuma das formas de classificação examinadas, uma vez que não obedece aos requisitos estabelecidos para cada uma delas, nem aos requisitos comuns a todas: que as classes sejam mutuamente excludentes e exaustivas. É observada a ausência de teorias, como a de 
Opções Reais e o Paradigma Eclético da Produção Internacional, para citar algumas, o que fere o princípio da exaustividade; e suspeita-se que as classes não sejam mutuamente excludentes, ou seja, um mesmo trabalho poderá utilizar simultaneamente duas ou mais classes (isto é, filiar-se a duas ou mais teorias). Infelizmente, a ausência de uma seção sobre metodologia, explicitando como foi feito o julgamento para que um artigo fosse classificado em uma classe ou outra, seleção de juízes, critérios utilizados etc., torna difícil, senão impossível, avaliar plenamente a adequação metodológica do artigo aos requisitos aqui examinados.

Uma vez feitas essas observações parece que qualquer esforço para avaliar a configuração de pesquisas em alianças estratégicas não pode fugir ao entendimento daquilo que Miller (1999, p. 27) chamou de "sistemas complexos de interdependência e os temas centrais que regem sua organização". Na verdade, o argumento é de que os esforços classificatórios são ainda prematuros, enquanto não tiverem sido mapeados os clusters de autores influentes no campo de estudos. Na seção seguinte, é feita uma proposta metodológica sobre como realizar o mapeamento proposto, o que é um passo fundamental para identificar os sistemas de inter-relações das teorias com os temas centrais subjacentes.

\section{UMA ABORDAGEM REALISTA: MÉTOdOS BibLIOMÉTRICOS}

No documento de Vale e Lopes inexiste uma seção sobre metodologia, embora os autores tenham incluído na introdução a seguinte indicação:

Para viabilizar sua realização foi utilizado, como método básico de investigação, uma revisão e análise crítica da literatura sobre estratégia, incluindo obras que contêm nos títulos, como indexadores ou abstracts, os termos cooperação, parceria, aliança e rede. Foi avaliado um total de 182 obras, incluindo 12 livros, uma tese de doutorado, 11 publicações constantes em anais de eventos internacionais e 158 artigos. Estes, provenientes dos seguintes periódicos: Academy of Management Journal, Academy of Management Executive, Academy of Management Review, Administrative Science Quarterly, California Management Review, Harvard Business Review, Journal of International Business Studies, Journal of Management, Journal of the Academy of Marketing Sciences, Planning Review, Organization Studies, Organization Science, Organizational Science, Networks and Organizations, The American Economic Review, Strategic Management Journal, The Journal of Economic Perspectives, Strategic Organization, RAE, RAC, RAUSP). Salienta-se que $30 \%$ das obras revisadas foram selecionadas para serem incluídas no referencial bibliográfico.

É recomendável, em estudos desta natureza, ao invés de usar livros, teses ou anais de congressos, considerar somente artigos de publicações qualificadas, porque estes podem ser considerados certified knowledge, citando Ramos-Rodriguez e Ruíz-Navarro (2004). A escolha de tais publicações também deve observar critérios rígidos, como indexação a bases de dados, que permitam a avaliação de fatores de impacto, e julgamento de relevância para a área de conhecimento, realizado preferencialmente por um júri de especialistas. O horizonte temporal da análise deve ser fixado.

O termo bibliometria compreende a análise matemática e estatística de padrões surgidos na publicação e uso de documentos. Entre as opções oferecidas pela bibliometria sugere-se adotar a análise de co-citação de autores (Author Co-Citation Analysis [ACA]), como método objetivo, capaz de promover a metamorfose de impressionismo em realismo. Casillas e Acedo (2007) citam aplicações em management, marketing, comportamento organizacional, pequenas empresas, sistemas de informações gerenciais, administração estratégica e negócios internacionais. Destacam ainda que esta metodologia contribui para a identificação de lacunas de pesquisa e orientação de futuras investigações. 
ACA estuda a frequência conjunta de citações de documentos ou autores, identificando grupos que podem ser considerados como pertencentes ao mesmo domínio de pesquisa ou a linhas de pensamentos similares. Por exemplo, Ramos-Rodriguez e Ruíz-Navarro (2004) analisaram as alterações na estrutura intelectual da pesquisa em administração estratégica por meio de um estudo bibliométrico com base nos artigos publicados no Strategic Management Journal de 1980 a 2000.

Foram investigados 1045 autores e 870 artigos, compreendendo 41.674 referências a 21.696 trabalhos diferentes, com uma média de 47,9 referências por artigo. O projeto do estudo empírico permitiu a identificação da estrutura intelectual da pesquisa em administração estratégica, conforme ilustrado na Figura 1.

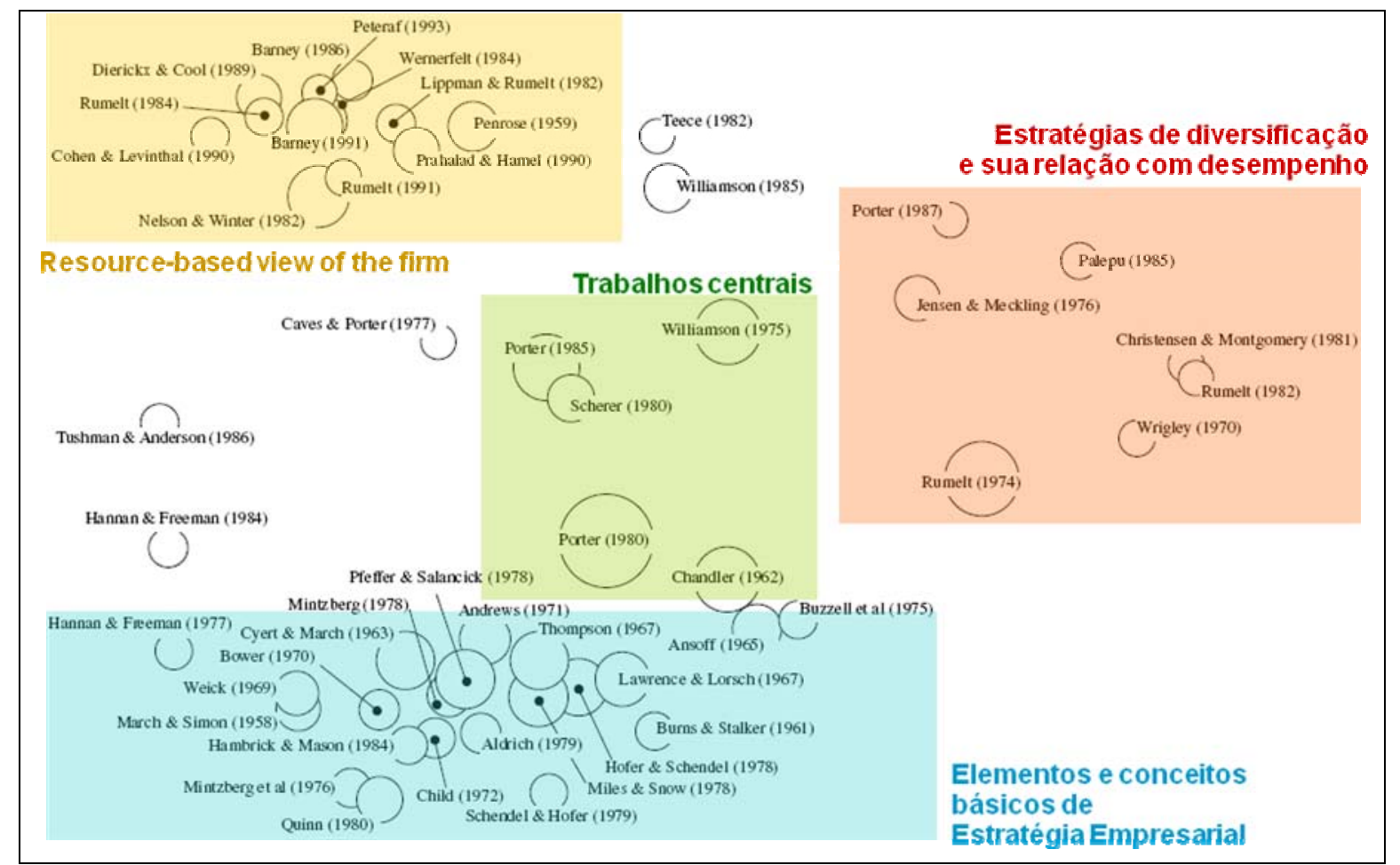

Figura 1: Estrutura Intelectual da Pesquisa em Administração Estratégica de 1980 a 2000

Fonte: Ramos-Rodriguez, A. R., \& Ruíz-Navarro, J. (2004). Changes in the intellectual structure of strategic management research: a bibliometric study of the Strategic Management Journal, 1980-2000 (p. 993). Strategic Management Journal, 25(10), 981-1004.

A figura resulta da aplicação de Multidimensional Scaling aos dados de uma matriz de co-citações construída a partir de contagens na base de dados selecionada. O gráfico de bolhas sobreposto ao mapa possibilita avaliar a importância de cada citação na estrutura (quanto maior a bolha, mais relevante o artigo). Os quatro setores sombreados derivam da análise dos resultados e identificam as grandes correntes de produção intelectual: Trabalhos centrais, Elementos e conceitos básicos de estratégia empresarial, Estratégias de diversificação e sua relação com desempenho e Visão da empresa baseada em recursos. Três trabalhos ficaram isolados.

Seria desejável obter resultados similares para a estrutura intelectual da pesquisa em alianças estratégicas e, a partir do mapeamento dos resultados, identificar teorias ou linhas de pensamento alternativas. 


\section{COMENTÁRIOS FINAIS}

É claro que a metodologia sugerida apresenta limitações. A primeira derivada da seleção de publicações a serem analisadas que poderão, eventualmente, excluir da amostra documentos /autores importantes, especialmente se a seleção for concentrada geograficamente. O tempo de vida das publicações também imporá restrições longitudinais aos resultados.

A segunda é relacionada à aplicação de técnicas bibliométricas. Conforme ressaltado por Casillas e Acedo (2007), ACA tem como premissa a proximidade conceitual ou metodológica de trabalhos citados compartilhadamente, embora tal ponto não possa ser demonstrado para todos os casos. Adicionalmente, os trabalhos mais recentes são subavaliados por uma questão temporal. Finalmente, é bom lembrar que citação não é sinônimo de importância ou relevância.

Credita-se a Mao Tse Tung a frase: "toda grande marcha começa com um primeiro passo". Vale e Lopes tiveram este privilégio, na grande marcha para entender a pesquisa em alianças estratégicas. Trata-se de tema complexo e muito fragmentado, o que provavelmente gerará um mapeamento de estrutura intelectual com mais clusters, de menores dimensões e fronteiras mais difusas do que aqueles determinados para a administração estratégica.

\section{REFERÊNCIAS BIBLIOGRÁFICAS}

Astley, W., \& Fombrum, C. (1983). Collective strategy: social ecology of organizational environments. Academy of Management Review, 8(4), 576-587.

Barney, J. (2006). Gaining and sustaining competitive advantage (3rd ed.). Englewood Cliffs, NJ: Prentice-Hall.

Carper, W. B., \& Snizek, W. E. (1980). The nature and types of organizational taxonomies: an overview. Academy of Management Review, 5(1), 65-75.

Casillas, J., \& Acedo, F. (2007). Evolutions of the intellectual structur of family business literature: a bibliometric study of FBR. Family Business Review, 20(2), 141-162.

Chrisman, J. J., Hofer, C. W., \& Boulton, W. R. (1988). Toward a system for classifying business strategies. Academy of Management Review, 13(3), 413-428.

Doty, D. H., \& Glick, W. H. (1994). Typologies as a unique form of theory building: toward improved understanding and modeling. Academy of Management Review, 19(2), 230-251.

Dunning, J. (1995). Reappraising the eclectic paradigm in an age of alliance capitalism. Journal of International Business Studies, 26(3), 461-491.

Gomes-Casseres, B. (1996). The alliance revolution: the new shape of business rivalry. Cambrigde, MA: Harvard University Press.

Gulati, R. (1998). Alliances and networks. Strategic Management Journal, 19(4), 293-317.

Klein, S., \& Zif, J. (1994). Global versus local strategic alliances. Journal of Global Marketing, 8(1), 51-71.

Kogut, B. (2000). The network as knowledge: generative rules and the emergence of structure. Strategic Management Journal, 21(3), 405-425. 
McKelvey, B. (1978). Organizational systematic: taxonomic lessons from Biology. Management Science, 24(13), 1428-1440.

Meyer, A. D., Tsui, A. S., \& Hinnings, C. R. (1993). Configurational approaches to organizational analysis. Academy of Management Journal, 36(6), 1175-1195.

Miller, D. (1996). Configurations revisited. Strategic Management Journal, 17(7), 505-512.

Miller, D. (1999). Notes on the study of configurations. Management International Review, 39(2), 27-39.

Pinho, C. R. A. (1998). Alianças estratégicas: conceituação, sistematização e avaliação. Dissertação de mestrado, Universidade Federal do Rio de Janeiro, Rio de Janeiro, RJ, Brasil.

Popper, K. (1978). Conjectures and refutations. London: Routledge.

Ramos-Rodriguez, A. R., \& Ruíz-Navarro, J. (2004). Changes in the intellectual structure of strategic management research: a bibliometric study of the Strategic Management Journal, 1980-2000. Strategic Management Journal, 25(10), 981-1004.

Rich, P. (1992). The organizational taxonomy: definition and design. The Academy of Management Review, 17(4), 758-781.

Williamson, O. (1975). Markets and hierarchies: an analysis and antitrust implications. New York: The Free Press. 